\title{
The History of Treatment of Twin-to-Twin Transfusion Syndrome
}

\author{
Chelsea L. Glennon, ${ }^{1}$ Scott A. Shemer, ${ }^{1}$ Ricardo Palma-Dias, ${ }^{1,2}$ and Mark P. Umstad ${ }^{1,2}$ \\ ${ }^{1}$ Department of Maternal Fetal Medicine, The Royal Women's Hospital, Melbourne, Victoria, Australia \\ ${ }^{2}$ Department of Obstetrics and Gynaecology, The University of Melbourne, Melbourne, Victoria, Australia
}

\begin{abstract}
Historical suggestions of twin-to-twin transfusion syndrome (TTTS) date back to the early 17th century. Placental anastomoses were first reported in 1687; however, it was Schatz who first identified their importance in 1875. He recognized 'the area of transfusion' within the 'villous district' of the placenta, which he named the 'third circulation'. This article describes how the management of TTTS has evolved as we have gained a more sophisticated understanding and appreciation of the complex vascular anastomoses that exist in monochorionic twin placentae. Currently, fetosopic laser occlusion is the preferred treatment option for TTTS.
\end{abstract}

Keywords: twin-to-twin transfusion, placental anastomoses, amnioreduction, fetoscopic laser coagulation

\section{The History of Treatment of Twin-to-Twin Transfusion Syndrome}

TTTS is caused by unbalanced vascular anastomoses within the placenta (Acosta-Rojas et al., 2007; Lewi et al., 2008; Quintero, 2003). Historically, TTTS has conferred an almost universal perinatal mortality, with a high incidence of disability in surviving twins (Quintero, 2003; Weir et al., 1979). With the introduction of targeted therapy, particularly fetoscopic laser ablation, outcomes have significantly improved.

\section{Early Descriptions of Twin Placental Anastomoses}

Stalpart van der Wiel first described 'passing vessels in twin placentas' in 1687 (Van der Wiel, 1687). Significant progress was then made in the mid-19th century by Spaeth (1860) and Heuter (1845), who described anastomoses in monochorionic placentae. In 1870, the Austrian anatomist Hyrtl produced an atlas of injected twin placentae demonstrating superficial and deep anastomoses.

However, it was Schatz, a German obstetrician, who was the first to recognize the importance of placental anastomoses in 1875 (Schatz, 1875). Following delivery, Schatz immediately warmed the placenta, washed out the blood, and then injected colored solutions, thereby demonstrating inter-twin vascular anastomoses. He observed that this occurred only in 'identical twin' pregnancies. He then provided a more comprehensive description of the fetoplacental circulation in 1886, studying 24 twin placentae where he noted three circulatory systems facilitating inter-twin transfusion. In addition to the two individual circulations, he recognized 'the area of transfusion' within the 'villous district' of the placenta, which he named the 'third circulation' (Schatz, 1886). He believed that $5-10 \%$ of the blood volume of each twin was within this 'third circulation', which consisted of arterioles of one twin uniting with venules of the other (Schatz, 1886). Schatz was the first to suggest an active 'hydraulic system' of the inter-fetal circulation, realizing the potential for harmful effects.

Many subsequent investigators have since contributed to the knowledge of inter-fetal circulatory anatomoses (Gedda, 1961). During the 1920s, Mutel and Vermelin identified variable depths of anastomoses. They reported that superficial anastomoses maintain equal pressures between the two circulations, whereas deep anastomoses cause an imbalance between the arterial and venous flow. Furthermore, they suggested that compensation could be achieved via superficial anastomoses, or by vasculogenesis of a second deep branch to neutralize the hemodynamic volumes (Gedda, 1961). Resinelli and Ferroni, in 1940, recognized that

RECEIVED 2 March 2016; ACCEPTED 10 March 2016.

ADDRESS FOR CORRESPONDENCE: Associate Professor Mark P. Umstad, The Royal Women's Hospital, 20 Flemington Road, Parkville 3052 VIC, Australia. E-mail: mark.umstad@ thewomen.org.au 
anastomoses are usually balanced; however, when the superficial vessels can no longer compensate for the deep vessel disparity, there is an asymmetry within the third circulation, subsequently resulting in functional, anatomical, and pathological conditions within the twins (Gedda, 1961). These findings were affirmed by Werner, who created casts of both superficial and deep anastomoses (Gedda, 1961). In 1948, De Camillis and Tammeo injected radio-opaque dye into the vasculature of twin placentae, identifying the number, volume, position, and nature of anastomoses via X-ray (Gedda, 1961). Through this technique, they demonstrated that arteriovenous anastomoses are always deep, and the number of these should be equal in each direction.

\section{Diagnosis of TTTS}

The earliest suggestion of TTTS dates back to the book of Genesis, which describes the birth of Esau and Jacob, the twin boys of Isaac and Rebecca. Esau, the firstborn, emerged 'red all over' and Jacob was born pale, representing the recipient and donor twin, respectively.

De Wikkellkinderen (The Swaddled Children), painted in 1617 , illustrates twin boys, one pale and the other plethoric. This is now thought to depict TTTS (Berger et al., 2000).

Schatz was the first author to describe TTTS in 1886 . He illustrated grossly discordant twins, one who was larger and 'oedematous', and the other who was growth restricted and 'shrivelled'. The 'oedematous' twin died at 12 hours with a distended bladder at autopsy, whereas the 'stuck twin' died at 53 hours with an empty bladder. After recognizing this as sequelae of unbalanced anastomoses, he hypothesized that the 'third circulation' predominated and resulted in TTTS (Schatz, 1886; Urig et al., 1990). He inferred that the recipient twin was oedematous, had polyhydramnios secondary to excessive intrauterine urination, and developed cardiac failure leading to hepatosplenomegaly and ascites.

In 1965, Naeye, an American pathologist, offered a more sophisticated understanding of TTTS. He identified the effect of chronic nutritional deprivation on the size of organs in the donor twin, while appreciating that transfusion to the recipient increased the hemoglobin concentration and hematocrit, with subsequent cardiomyopathy and hypertension (Naeye, 1965). Traditionally, this discordant neonatal inter-twin hemoglobin concentration was used in the diagnosis of TTTS, as was a difference in skin color and birth weight discrepancy of greater than $20 \%$ (Ropacka et al., 2002; Taylor \& Fisk, 2005).

From the early 1980s, advanced ultrasonography was used to confirm the role of arteriovenous anastomoses in TTTS. Bajora used ultrasound to compare vasculature in monochorionic placentae, demonstrating a single deep arteriovenous anastomosis in TTTS, suggesting that a paucity of vascular connections caused unequal blood flow between the two halves of the placenta (Bajora et al., 1995).
The role of ultrasound in the assessment of TTTS assumed greater importance in the following years. Suzuki, in 1999, studied middle cerebral artery (MCA) and umbilical artery (UA) doppler waveforms of growth restricted fetuses with TTTS, and identified significantly higher MCA pulsatility index (PI) and UA PI values in the smaller twin (Suzuki et al., 1999). These results suggested an absence of blood flow redistribution in growth restricted fetuses affected by TTTS.

In 1999, Quintero used ultrasound criteria to standardize the staging of TTTS (Quintero et al., 1999). His classification remains in effect today.

\section{The Chronology of TTTS Treatments}

\section{Expectant Management and Natural History}

Traditionally, the natural history of TTTS is of almost certain fetal mortality, with other severe complications, including worsening polyhydramnios with subsequent premature birth, and hydrops secondary to cardiac failure (Weir et al., 1979). Quintero's staging system affords the ability to predict prognosis by stage. Untreated, Stage I TTTS confers an $86 \%$ overall survival rate, with progression to a higher stage in $10-30 \%$ percent of patients; that is, three quarters of patients with stage I TTTS remain stable or regress spontaneously (Bebbington et al., 2010; Rossi \& D'Addario, 2013).

In $5 \%$ of cases of Stage I or II disease, fetal demise of one or both twins can occur without warning (O'Donoghue et al., 2007; Senat et al., 2004).

Although no randomized control trials for expectant management of stages II to IV have been performed (Society for Maternal-Fetal Medicine \& Simpson, 2013), available data shows that the natural history of advanced TTTS is extremely poor, with a $70-100 \%$ perinatal mortality rate, particularly when it presents earlier than 26 weeks' gestation (Berghella \& Kaufmann, 2001; Gul et al., 2003). As such, expectant management often leads to the demise of at least one twin, with loss of the remaining twin in $12 \%$ of cases (Ong et al., 2006) and mortality and severe disability in approximately $50 \%$ of surviving co-twins (Van Heteren et al., 1998).

\section{Amnioreduction}

Therapeutic amnioreduction may be undertaken from 15 weeks' gestation, when the deepest vertical pocket (DVP) in the recipient sac is greater than $8 \mathrm{~cm}$, to achieve a DVP of less than 5-6 cm (Crombleholme et al., 2007; Senat et al., 2004). The aim is to reduce the polyhydramnios and, as a consequence, reduce the risk of preterm labor.

In addition, by reducing the liquor volume, the resultant decrease in the intra-amniotic and placental vasculature pressures improves placental blood flow (Garry et al., 1998). There is also a $74 \%$ increase in uterine artery blood flow, 
which too may play a role in improving fetal condition (Bower et al., 1995).

Releasing the pressure on the veno-venous anastomoses may allow them to regain compensatory function, and return the placenta 'from being flat and stretched to plump' (Machin \& Keith, 1999).

Early series removed small volumes of amniotic fluid, as it was thought that removing larger volumes may precipitate placental abruption or preterm labor (Cabrera-Ramirez \& Harris, 1976). In 1980, Mills suggested repeated drainage to maintain liquor volumes close to normal (Mills, 1980). Feingold et al. (1986) then described two cases whereby $3500 \mathrm{~mL}$ and $4750 \mathrm{~mL}$ of amniotic fluid were removed, prolonging the pregnancy by 14 and 11 days, respectively; two of the four fetuses survived. They concluded that decompressive amniocentesis 'can offer some hope to an otherwise hopeless situation'. Several authors have demonstrated improved clinical outcomes with aggressive repeated therapeutic amniocentesis before the onset of preterm labor, with relatively few complications (Elliot et al., 1991; Saunders et al., 1992; Urig et al., 1990). Consequently, serial amnioreduction was first-line treatment for severe TTTS in the 1990s.

A literature review, comprising 256 fetuses from 26 studies, including cases dating back to the 1930s, reported an overall survival rate of $49 \%$ following serial amnioreduction in the treatment of TTTS (Moise, 1993). More recent data shows an average survival rate of 50-65\% (Dickinson \& Evans, 2000; Mari et al., 2001); this figure is as high as $77 \%$ if treatment is initiated during Stage I disease (Rossi \& D’Addario, 2013). However, subsequent reviews no longer support amnioreduction as the first-line treatment for TTTS, unless other more sophisticated methods are unavailable or while awaiting transfer to another center (Roberts et al., 2008).

\section{Fetoscopic Laser Occlusion}

Fetoscopic laser coagulation of vascular communications between the fetoplacental circulations aims to dichorionize the placenta. In 1984, obstetrician Dr Julian DeLia and placental pathologist Dr Kurt Benirschke developed a technique to interrupt the inter-twin vascular anastomoses involved in TTTS. The experimental technique was first performed on ewes and monkeys using a neodymium:yttriumaluminium-garnet (Nd:YAG) laser (DeLia et al., 1989; DeLiad et al., 1985). On October 3, 1988, after years of using placental and animal models, DeLia performed the first fetoscopic laser ablation on a human patient at the University of Utah Health Sciences Center. In 1990, he described the outcomes of a further two cases at risk of preterm labor from acute polyhydramnios (DeLia et al., 1990). Two of the three cases were uncomplicated, with success in coagulating all of the superficial vascular anastomoses on the chorionic surface; the third had placental vessel perforation. The pregnancies were prolonged by between 7 and 12 weeks, and four of the six infants survived. This technique was performed under general or regional anesthesia, with laparotomy and hysterotomy for endoscopy and laser ablation.

In 1992, Ville et al. developed a less invasive technique using local anesthesia and percutaneous endoscopic laser coagulation (Ville et al., 1992). Ville et al. (1995) then described a method of systematic non-selective coagulation of all surface chorionic vessels crossing or adjacent to the inter-twin membrane in order to interrupt the afferent and efferent branches of the deeper arteriovenous anatomoses. Ville et al. (1998) published a study of 132 patients with severe TTTS, reporting an overall survival rate of 55\%, with single-twin survival in 73\%. DeLia et al. (1999) then recorded a $69 \%$ overall survival rate, with $82 \%$ of pregnancies having at least one survivor.

A meta-analysis of non-selective ablation for severe TTTS presenting prior to 28 weeks' gestation demonstrated an overall survival rate of $58 \%$, with at least one survivor in $74 \%$ of cases, a rate comparable to serial amnioreduction (Fisk et al., 2000). It is hypothesized that limited improvement in survival was attributable to the fact that the intertwin membrane does not necessarily represent the 'vascular equator' between the two fetoplacental circulations. Thus, necessary non-anastomotic vessels are sacrificed, consequently obliterating perfusion to cotyledons (DeLia et al., 2000; Thilaganathan et al., 2000). This is supported by postpartum pathological findings of areas of complete placental necrosis (DeLia et al., 1990), with this placental insult primarily affecting the donor twin.

This prompted Quintero et al. (1998) to develop an alternative technique whereby the anastomoses between the interfetal circulations were identified and coagulated - 'selective laser coagulation'. Quintero et al. (2000) reported that this selective method yielded superior results, with survival of at least one infant in $83 \%$ of patients. Hecher et al. (1999) achieved similar results, with overall survival of $68 \%$ using selective laser techniques, compared with $61 \%$ using a non-selective method, and 51\% with amnioreduction.

Quintero et al. (2007) then proposed a sequential approach to selective laser ablation. Here, the anastomotic vasculature is first mapped, and anastomoses are then coagulated in an arteriovenous, venoarterial, and finally arterioarterial sequence. This resulted in decreased fetal demise (7.3\% vs. $21.4 \%)$ and improved dual perinatal survival (73.7\% vs. $57.1 \%)$ compared to non-sequential selective laser ablation.

Lopriore et al. (2009) and Chalouhi et al. (2011) suggested superficial coagulation of microvasculature on the chorionic plate between ablated anastomotic sites following selective laser occlusion. This 'Solomon technique' thereby creates a distinct separation of the two fetal vascular territories on the surface of the placenta. It has been shown to improve both double-twin survival and overall neonatal survival, with rates of $84.6 \%$ and $86.5 \%$, respectively. It 
may also play a role in preventing recurrence or twin anemia polycythaemia sequence (TAPS) by reducing the incidence of residual small anastomoses (Ruano et al., 2013).

Currently, fetoscopic laser ablation is accepted as the first-line treatment for stage II to IV TTTS in pregnancies under 26 weeks' gestation (SMFM \& Simpson, 2013).

\section{Medical Management}

Medical therapies are most commonly used in conjunction with interventional amnioreduction or laser ablation. DeLia et al. (1985) first suggested the use of maternal digoxin therapy in the setting of persistent signs of cardiac failure in the recipient twin. He demonstrated resolution of cardiac decompensation, and both twins survived. Subsequent authors have since evaluated digoxin as an adjunct to laser or amnioreduction with successful results (Arabin et al., 1998; Roman \& Hare, 1995); however, the evidence is limited, and digoxin is no longer prescribed for management of TTTS.

Several studies have evaluated the role of indomethacin in prolonging pregnancy. Indomethacin reduces fetal renal perfusion and consequently polyhydramnios. The use of indomethacin was first described by Cabrol et al. (1987). However, it has subsequently been shown to worsen oligohydramnios in the donor twin and is rarely used (Demandt et al., 1990).

More recently, a case-control study suggested a role for nifedipine in addition to selective laser ablation. Crombleholme et al. (2010) reported improved outcomes in the recipient twin with maternal administration of nifedipine 24-48 hours prior to laser occlusion in 141 cases of TTTS with evidence of fetal cardiomyopathy.

At present, medical management is not recommended as either a first-line or routine adjunctive therapy in the treatment of TTTS.

\section{Septostomy}

Septostomy allows equilibration of amniotic fluid volumes between twins. This corrects polyhydramnios, and possibly improves the hemodynamic status of the donor by allowing for oral rehydration and improved fluid resorption. It was initially described following inadvertent iatrogenic puncture of the amnion in the septum at the time of amnioreduction (Saade et al., 1995). Saade et al. (1998) then published a series of 12 cases and reported $83 \%$ perinatal survival, prompting the commencement of a randomized control trial comparing the results to amnioreduction. Two studies have concluded no significant difference in overall perinatal survival, although septostomy often avoids the need for repeat procedures, in contrast to amnioreduction (Moise et al., 2005; Saade et al., 2002). Septostomy, however, is associated with a risk of disrupting the inter-twin membrane, thereby creating a functional monoamniotic gestation. This confers a risk of cord entanglement and double-twin demise (Cook \& O’Shaughnessy, 1997; Taylor
\& Fisk, 2005). It has subsequently been abandoned as a form of treatment for TTTS.

\section{Selective Feticide}

Selective reduction involves interrupting the transfusion process by intentional feticide of one twin. It is imperative that all vascular connections are occluded simultaneously to prevent exsanguination from one twin to the other. Although unsuccessful, it was first performed in 1967 with cord ligation (Benirschke \& Driscoll, 1967). Since then, many other techniques have been used, including interstitial laser coagulation, radiofrequency ablation, and bipolar cord coagulation. A systematic review reported an average survival rate of $79 \%$ in the remaining twin (Rossi \& D’Addario, 2009); however, there is limited data regarding neurological outcomes (Rossi et al., 2011).

In the 1990s, experimental ultrasound-guided sclerosant injection using alcohol or helical metal coils was also described; however, it was associated with high failure rates, as it only occludes one vessel (Saade et al., 1997).

A further method of selective reduction for TTTS involves bipolar cord coagulation, which was originally developed for acardiac or anomalous twins (Taylor et al., 2002). This technique uses bipolar diathermy forceps under ultrasound guidance with serial coagulation to occlude blood flow. Potential complications of selective feticide include preterm prelabor rupture of membranes (PPROM), preterm labor (Taylor et al., 2002), and embolic and coagulopathic effects in the surviving twin (Szymonowicz et al., 1986). This treatment option is therefore only reserved for severe cases of TTTS where the demise of one twin is imminent or extremely likely.

\section{Conclusion}

The effective treatment of TTTS relies on a sophisticated understanding and appreciation of the complex vascular anastomoses that exist in monochorionic twin placentae. History abounds with well-intentioned, carefully considered, but ultimately poorly successful treatments for TTTS. Fetoscopic laser ablation is currently the preferred option for management of this potentially devastating condition.

\section{References}

Acosta-Rojas, R., Becker, J., Munoz-Abellana, B., Ruiz, C., Carreras, E., \& Gratacos, E.; . (2007). Twin chorionicity and the risk of adverse perinatal outcome. International Journal Gynecology and Obstetrics, 96, 98-102.

Arabin, B., Laurini, R. N., van Eyck, J., \& Nicolaides, K. H. (1998). Treatment of twin-twin transfusion syndrome by laser and digoxin. Biophysical and angiographic evaluation. Fetal Diagnosis and Therapy, 13, 141-146.

Bajora, R., Wigglesworth, J., \& Fisk, N. M. (1995). Angioarchitecture of monochorionic placentas in relation to the twin-twin transfusion syndrome. American Journal of $\mathrm{Ob}$ stetrics and Gynecology, 172, 856-63. 
Bebbington, M. W., Tbilad, E., Huesler-Charles, M., Wilson, R. D., Mann, S. E., \& Johnson, M. P. (2010). Outcomes in a cohort of patients with stage I twin-to-twin transfusion syndrome. Ultrasound in Obstetrics \& Gynaecology, 36, 48-51.

Benirschke, K., \& Driscoll, S. G. (1967). The pathology of the human placenta. Berlin: Springer-Verlag.

Berger, H. M., de Ward, F., \& Molenaar, Y. (2000). A case of twin-to-twin transfusion in 1617. The Lancet, 356, 847-848.

Berghella, V., \& Kaufmann, M. (2001). Natural history of twin-twin transfusion syndrome. Journal of Reproductive Medicine, 46, 480-484.

Bower, S. J., Flack, N. J., Sepulveda, W., Talbert, D. G., \& Fisk, N. M. (1995). Uterine artery blood flow response to correction of amniotic fluid volume. American Journal of Obstetrics \& Gynecology, 173, 502-507.

Cabrera-Ramierz, L., \& Harris, R. E. (1976). Controlled removal of amniotic fluid in hydramnios. Southern Medical Journal, 69, 239-240.

Cabrol, D., Landesman, R., Muller, J., Uzan, M., Sureau, C., \& Saxena, B. B. (1987). Treatment of polyhydramnios with prostaglandin synthetase inhibitor (indomethacin). American Journal of Obstetrics \& Gynecology, 157, 422-426.

Chalouhi, G. E., Essaoui, M., Stirnemann, J., Quibel, T., Deloison, B., Salomon, L., \& Ville, Y. (2011). Laser therapy for twin-to-twin transfusion syndrome (TTTS). Prenatal Diagnosis, 31, 637-646.

Cook, T. L., \& O’Shaughnessy, R. (1997). Iatrogenic creation of a monoamniotic twin gestation in severe twin-twin transfusion syndrome. Journal of Ultrasound Medicine, 16, 853855.

Crombleholme, T. M., Lim, F. Y., Habli, M., Polzin, W., Jaekle, R., Michelfelder, E., ... Kim, M. O. (2010). Improved recipient survival with maternal nifedipine in twin-twin transfusion syndrome complicated by TTTS cardiomyopathy undergoing selective fetoscopic laser ablation. American Journal of Obstetrics \& Gynecolology, 203, 397e1-9.

Crombleholme, T. M., Shera, D., Lee, H., Johnson, M., D’Alton, M., Porter, F., . . Y Young, B. (2007). A prospective, randomized, multicentre trial of amnioreduction vs selective fetoscopic laser photocoagulation for the treatment of severe twin-twin transfusion syndrome. American Journal of Obstetrics \& Gynecology, 197, 396.e1-9.

DeLia, J. E., Cruikshank, D. P., \& Keye, W. R. Jr. (1990). Fetoscopic neodymium: YAG laser occlusion of placental vessels in severe twin-twin transfusion syndrome. Obstetrics \& $G y$ necology, 75, 1046-53.

DeLia, J. E., Cukierski, M. A., Lundergan, D. K., \& Kochenour, N. K. (1989). Neodymium-yttrium-aluminium-garnet laser occlusion of rhesus placental vasculature via fetoscopy. American Journal of Obstetrics \& Gynecology, 160, 485489.

DeLia, J. E., Emery, M. G., Sheafor, S. A., \& Jenninson, T. A. (1985). Twin transfusion syndrome: Successful in utero treatment with digoxin. International Journal of Gynaecology \& Obstetrics, 23, 197-201.

DeLia, J. E., Fisk, N., \& Hecher, K. (2000). Twin-to-twin transfusion syndrome - Debates on eitiology, natural history and management. Ultrasound of Obstetrics \& Gynecology, 16, 210-213.

DeLia, J. E., Kuhlmann, R. S., \& Lopez, K. P. (1999). Treating previable twin-twin transfusion syndrome with fetoscopic laser surgery: Outcomes following the learning curve. Journal of Perinatal Medicine, 27, 61-67.

DeLia, J. E., Rogers, J. G., \& Dixon, J. A. (1985). Treatment of placental vasculature with a neodymium-yttriumaluminium-garnet laser via fetoscopy. American Journal of Obstetrics \& Gynecology, 151, 1126-1127.

Demandt, E., Legius, E., Devlieger, H., Lemmens, F., Proesmans, W., \& Eggermont, E. (1990). Prenatal indomethacin toxicity in one member of monozygous twins: A case report. European Journal of Obsterics \& Gynecology, $35,267-269$.

Dickinson, J. E., \& Evans, S. F. (2000). Obstetric and perinatal outcomes from the Australian and New Zealand twin-twin transfusion syndrome registry. American Journal of Obstetrics \& Gynecology, 182, 706-712.

Elliot, J. P., Urig, M. A., \& Clewell, W. H. (1991). Aggressive therapeutic amniocentesis for the treatment of twin-twin transfusion syndrome. Obstetrics \& Gynecology, 77, 537544.

Feingold, M., Centrulo, C. L., Newton, E. R., Weiss, J., Shakr, C., \& Shmoys, S. (1986). Serial amniocentesis in the treatment in twin-twin transfusion syndrome complicated by acute polyhydramnios. Acta Geneticae Medicae et Gemellologiae, 35, 107-113.

Fisk, N. M., \& Taylor, M. J. O. (2000). The fetus(es) with twin twin transfusion syndrome. In M. Harrison, M. Evans, S. Adzick \& W. Holzgreve (Eds.), The unborn patient: The art and science of fetal therapy (pp. 341-355). Philadelphia: WB Saunders.

Garry, D., Lysikiewicz, A., Mays, J., Canterino, J., \& Tejani, N. (1998). Intra-amniotic pressure reduction in twin-twin transfusion syndrome. Journal of Perinatology, 18, 284286.

Gedda, L. (1961). Twins in history and science. Springfield, IL: Charles C. Thomas Publisher.

Gul, A., Slan, H., Polat, I., Cebeci, A., Bulut, H., Sahin, O., \& Ceylan, Y. (2003). Natural history of 11 cases of twin-twin transfusion syndrome without intervention. Twin Research, 6, 263-266.

Hecher, K., Plath, H., Bregenzer, T., Hansmann, M., \& Hackleor, B. J. (1999). Endoscopic laser surgery versus serial amniocentesis in the treatment of severe twin-twin transfusion syndrome. American Journal of Obstetrics \& Gynecology, 180, 717-724.

Heuter, C. C. (1845). Der einfache Mutterkuchen der Zwillinge. Marburg, Germany.

Hyrtl, J. (1870). Die Blutgefasse der menschlichen Nachgeburt in normalen und abnormen Verhaltnissen. Vienna, Austria.

Lewi, L., Jani, J., Blickstein, I., Huber, A., Gucciardo, L., Van Mieghem, T., ... Deprest, J. (2008). The outcome of monochorionic diamniotic twin gestation in the era of invasive fetal therapy: A prospective cohort study. American Journal of Obstetrics and Gynecology, 199, 514.e1-8. 
Lopriore, E., Slaghekke, F. P., Middleldorp, J. M., Klumper, F. J., Oepkes, D., \& Vandenbussche, F. P. (2009). Residual anastomoses in twin-to-twin transfusion syndrome treated with selective fetoscopic laser surgery: Localization, size, and consequences. American Journal of Obstetrics \& Gynecology, 201, e61-64.

Machin, G. A., \& Keith, L. G. (1999). An atlas of multiple pregnancy biology and pathology. London: The Parthenon Publishing Group.

Mari, G., Roberts, A., Detti, L., Kovanci, E., Stefos, T., BahadoSingh, R. O., ... Fisk, N. M. (2001). Perinatal morbidity and mortality rates in severe twin-twin transfusion syndrome: Result of international Amnioreduction registry. American Journal of Obstetrics \& Gynecology, 185, 708-715.

Mills, W. G. (1980). Letter to the editor. British Journal of Obstetrics \& Gynaecology, 87, 255.

Moise, K. J. (1993). Polyhydramnios: Problems and treatment. Seminars in Perinatology, 17, 197-209.

Moise, K. J. Jr., Dorman, K., Lamvu, G., Saade, G. R., Fisk, N. M, Dickinson, J. E., ... Skupski, D. (2005). A randomized trial of amnioreduction versus septostomy in the treatment of twin-twin transfusion syndrome. American Journal of Obstetrics \& Gynecology, 193, 701-707.

Mutel, M., \& Vermelin, H. (1928). Epitome of Current Medical Literature: Hydramnios with Uniovular Twins. British Medical Journal. Gynecologie et obstetrique. 217, 79-80.

Naeye, R. L. (1965). Organ abnormalities in human parabiotic syndrome. American Journal of Surgical Pathology, 46, 829842.

O’Donoghue, K., Cartwright, E., Galea, P., \& Fisk, N. M. (2007). Stage-I twin-twin transfusion syndrome: Rates of progression and regression on relation to outcome. Ultrasound in Obstetrics \& Gynecology, 30, 958-964.

Ong, S. S., Zamora, J., Khan, K. S., \& Kilby, M. D. (2006). Prognosis for the co-twin following single-twin death: A systematic review. British Journal of Obstetrics \& Gynaecology, 113, 992-998.

Quintero, R. A. (2003). Twin-twin transfusion syndrome. Clinical Perinatology, 30, 591-600.

Quintero, R. A., Comas, C., Bornick, P. W., Allen, M. H., \& Kruger, M. (2000). Selective versus non-selective laser photocoagulation of placental vessels in twin-twin transfusion syndrome. Ultrasound in Obstetrics \& Gynecology, 16, 230236.

Quintero, R. A., Ishii, K., Chmait, R. H., Bornick, P. W., Allen, M. H., \& Kontopoulos, E. V. (2007). Sequential selective laser photocoagulation of communicating vessels in twintwin transfusion syndrome. The Journal of Maternal-Fetal \& Neonatal Medicine, 20, 763-768.

Quintero, R. A., Morales, W. J., Allen, M. H., Bornick, P. W., Johnson, P. K., \& Kruger, M. (1999). Staging of twin-twin transfusion syndrome. Journal of Perinatology, 19, 550555.

Quintero, R. A., Morales, W. J., Allen, M., Bornick, P. W., \& LeParc, G. (1999). Treatment of iatrogenic previable premature rupture of membranes with intra-amniotic injection of platelets and cryoprecipitate (amniopatch): Preliminary experience. American Journal of Obstetrics \& Gynecology, 181, 744-749.

Quintero, R. A., Morales, W., Mendoza, G., Allen, M., Kalter, C., Giannina, G., \& Angel, J. L. (1998). Selective photocoagulation of placental vessels in twin-twin transfusion syndrome: Evolution of a surgical technique. Obstetrical \& Gynecological Survey, 53, s97-103.

Roberts, D., Gates, S., Kilby, M., \& Neilson, J. P. (2008). Interventions for twin-twin transfusion syndrome: A cochrane review. Ultrasound in Obstetrics \& Gynecolology, 31, 701711.

Roman, J. D., \& Hare, A. A. (1995). Digoxin and decompression amniocentesis for treatment of feto-fetal transfusion. British Journal of Obstetrics \& Gynaecology, 102, 421-423.

Ropacka, M., Markwitz, W., \& Blickstein, I. (2002). Treatment options for the twin-twin transfusion syndrome: A review. Twin Research, 5, 507-514.

Rossi, A. C., \& D’Addario, V. (2009). Umbilical cord occlusion for selective fetocide in complicated monochorionic twins: A systematic review of literature. American Journal of Obstetrics \& Gynecology, 200, 123-239.

Rossi, A. C., Vanderbilt, D., \& Chmait, R. (2011). Neurodevelopmental outcomes after laser therapy for twin-twin transfusion syndrome: A systematic review and meta-analysis. Obstetrics \& Gynecology, 118, 1145.

Rossi, C., \& D’Addario, V. (2013). Survival outcomes of twintwin transfusion syndrome in stage I: A systematic review of the literature. American Journal of Perinatology, 1, 5-10.

Ruano, R., Rodo, C., Peiro, J. L., Shamshirsaz, A. A., Haeri, S., Nomuras, M. L., ... Belfort, M. A. (2013). Fetoscopic laser ablation of placental anastomoses in twin-twin transfusion syndrome using 'Solomon technique'. Ultrasound in Obstetrics \& Gynecology, 42, 434-439.

Saade, G. R., Belfort, M. A., Berry, D. L., Bui, T. H., Montgomery, L. D., Johnson, A., ... Moise, K. J. (1998). Amniotic septostomy for the treatment of twin oligohydramnios-polyhydramnios sequence. Fetal Diagnosis and Therapy, 13, 86-93.

Saade, G. R., Ludomirsky, A., \& Fisk, N. M. (1997). Feto-fetal transfusion. In Fisk, N. M., \& Moise K. J. (Eds.), Transfusion in Fetal Therapy: Invasive and Transplacental. Cambridge: Cambridge University Press. p. 227.

Saade, G. R., Moise, K., Dorman, K., Fisk, N. M., Lmanvu, G., ... Dickinson, J. E. (2002). A randomized trial of septostomy versus amnioreduction in the treatment of oligohydramnios polyhydramnios sequence (TOPS). American Journal of Obstetrics \& Gynecology, 187, s54.

Saade, G. R., Olson, G., Belfort, M. A., \& Moise, K. J. (1995). Amniotomy: A new approach to the 'stuck twin' syndrome. American Journal of Obstetrics \& Gynecology, 172, 429431.

Saunders, N. J., Smijders, R. J. M., \& Nicolaides, K. H. (1992). Therapeutic amniocentesis in twin-twin transfusion syndrome appearing in the second trimester of pregnancy. American Journal of Obstetrics \& Gynecology, 166, 820-824.

Schatz, F. (1875). Ueber die wahrend jeder Geburt eintretende relative Verkurzung oder Verlangerung der Nabelschnur und die dadurch unter bestimmten Umstanden bedingten 
Storungen und Gafahren der Geburt. Archives of Gynaecology, 8, 1-47.

Schatz, F. (1886). Die Gef, sseverbindungen der Placentarkreisl, ufe eineiiger Zwillinge, ihre Entwicklung und ihre Folgen. Archives of Gynaecology, 27, 1-72.

Senat, M. V., Deprest, J., Boulvain, M., Paupe, A., Winer, N., \& Ville, Y. (2004). Endoscopic laser surgery versus serial amnioreduction for severe twin-to-twin transfusion syndrome. New England Journal of Medicine, 351, 136144.

Society for Maternal-Fetal Medicine (SMFM), \& Simpson, L. L. (2013). Twin-twin transfusion syndrome. American Journal of Obstetrics and Gynecology, 208, 3-18.

Spaeth, J. (1860). Studien uber Zwillnige. Zschr Gesell Aerzte Wien, 15, 225-231; 16, 241-244.

Stalpart Van Der Wiel, C. (1687). Observationum rariorum medic. anatomic. chirurgicarum centuria prior, accredit de unicornu dissertation. Apud Petrum vander Aa: Lugduni Batavorum.

Suzuki, S., Sawa, R., Yoneyama, Y., Otsubo, Y., \& Araki, T. (1999). Fetal middle cerebral artery Doppler waveforms in twin-twin transfusion syndrome. Gynecologic and Obstetric Investigation, 48, 98-101.

Szymonowicz, W., Preston, H., \& Yu, V. Y. H. (1986). The surviving monozygotic twin. Archives of Diseases in Childhood, 61, 454-458.

Taylor, M. J. O., \& Fisk, N. M. (2005). Management of twintwin transfusion syndrome. In I. Blickstein \& L. G. Keith (Eds.), Multiple pregnancy - Epidemiology, gestation \& perinatal outcome (2nd ed., pp. 552-570). Oxon, UK: Informa UK.

Taylor, M. J., Shalev, E., Tanawattanacharoen, S., Jolly, M., Kumar, S., Weiner, E., ... Fisk, N. M. (2002). Ultrasoundguided umbilical cord occlusion using bipolar diathermy for stage III/IV twin-twin transfusion syndrome. Perinatal Diagnosis, 22, 70-76.

Thilaganathan, B., Gloeb, D. J., Sairam, S., \& Tekay, A. (2000). Sono-endoscopic delineation of the placental vascular equator prior to selective fetoscopic laser ablation in twinto-twin transfusion syndrome. Ultrasound in Obstetrics \& Gynecology, 16, 269-269.

Urig, M. A., Clewell, W. I., \& Elliot, J. P. (1990). Twin-twin transfusion syndrome. American Journal of Obstetrics and Gynaecology, 163, 1522-1526.

Van der Wiel, S. (1687). Observationum rariorum medic. anatomic chirurgicarum centúria prior, accedit de unicornu dissertativo. Lugduni Batavorum: apud Petrum van der Aa, 1, 329-330.

van Heteren, C. F., Nijhuis, J. G., Semmekrot, B. A., Mulders, L. G., \& van den Berg, P. P. (1998). Risk of the surviving twin after fetal death of co-twin in twin-twin transfusion syndrome. Obstetrics and Gynecology, 92, 215-219.

Ville, Y., Hecher, K., Gagon, A., Sebire, N., Hyett, J., \& Nicolaides, K. (1998). Endoscopic laser coagulation in the management of severe twin-to-twin transfusion syndrome. British Journal of Obstetrics \& Gynaecology, 105, 446-453.

Ville, Y., Hecker, K., Ogg, D., Warren, R., \& Nicolaides, K. (1992). Successful outcome after Nd:YAG laser separation of chorioangiopagus-twins under sonoendoscopic control. Ultrasound in Obsteterics \& Gynecology, 2, 429-431.

Ville, Y., Hyett, J., Hecher, K., \& Nicolaides, K. (1995). Preliminary experience with endoscopic laser surgery for severe twin-twin transfusion syndrome. New England Journal of Medicine, 332, 224-232.

Weir, P. E., Ratten, G. J., \& Beischer, N. A. (1979). Acute polyhydramnios - A complication of monozygous twin pregnancy. British Journal of Obstetrics and Gynaecology, 86, 849-853. 